\title{
Assessment of a Public Participation Tool by Experts: A Case Study of Quebec, Canada
}

\author{
Anne Bernard, Nancy Gélinas \\ Département des Sciences du Bois et de la Forêt, Université Laval, Quebec City, Canada \\ Email: anne.bernard.1@ulaval.ca,nancy.gelinas@sbf.ulaval.ca
}

How to cite this paper: Bernard, A. and Gélinas, N. (2020) Assessment of a Public Participation Tool by Experts: A Case Study of Quebec, Canada. Natural Resources, 11, 283-306.

https://doi.org/10.4236/nr.2020.117017

Received: June 24, 2020

Accepted: July 20, 2020

Published: July 23, 2020

Copyright $\odot 2020$ by author(s) and Scientific Research Publishing Inc. This work is licensed under the Creative Commons Attribution International License (CC BY 4.0).

http://creativecommons.org/licenses/by/4.0/

(c) (i) Open Access

\begin{abstract}
In theory, sustainable forest management (SFM) puts public participation at the epicenter of the decision-making process. However, in reality, the situation is different. The growing importance of public participation seems essential for the implementation of sustainable forest management. The aim of this study is to assess the implementation of a theoretical concept closely related to SFM, integrated land and resource management (ILRM). This Canadian concept aims to integrate many forest functions using participatory tools. Using semi-structured interviews with experts, we clarify our theoretical concept and adapt it to reality. Our results show that better communication between stakeholders is necessary. It is also important to increase the flexibility of the timber harvest system and adapted forest zoning should be considered. A new concept, the forest culture, seems to be a key element that needs to be considered upstream of forest management. A new definition of ILRM is proposed in order to better reach social values.
\end{abstract}

\section{Keywords}

Consultation Process, Sustainable Forest Management (SFM), Case Study, Public Participation, Multiple-Use Management, Canada

\section{Introduction}

Since the end of the 1980s and until the beginning of the 2000s, nearly a hundred major international conferences have been held addressing the subject of sustainable management. We usually think of the Rio Conference (1992) and its Agenda 21 to promote sustainable development. But since this conference, a plethora of conferences and reports have been launched to promote the participation of countries, larger and smaller administrative government units, industries, NGOs, communities and so on, with the goal of achieving sustainable for- 
est management (SFM) targets. Thus, these international meetings now have direct impacts on local policies and regional concerns as sustainable forest management has been recognized as the key concept guiding the management of the world's forests. Most modern forest policies are now developed around SFM that is defined as "the process of managing forests to achieve one or more clearly specified objectives of management with regard to the production of a continuous flow of desired forest products and services, without undue reduction of its inherent values and future productivity and without undue undesirable effects on the physical and social environment" [1].

This paper assesses the implementation of a theoretical concept that aims to contribute to SFM goals and to various functions of forest ecosystems, the integrated land and resource management (ILRM) approach. Although this approach is close to multiple-use forest management, ILRM is only used on public land in Canada. The goal of this approach is the cohabitation of stakeholders within the forest to strive for collective well-being. The heart of the ILRM process is to consider the needs, values and expectations of the stakeholders. The next section presents the theoretical background of the ILRM process. The following section presents a case study of the province of Quebec and its forest management regulations. The third section shows the methodological approach used to collect the qualitative data. The results and discussion section present a global assessment of ILRM implementation and new ideas that have emerged following interviews. We conclude the paper with key elements that should be considered to reach theoretical and regulatory ILRM objectives in the field.

\subsection{ILRM, a Theoretical Concept}

The current concept of ILRM comes from multiple-use forest management that was inspired first by American foresters from the late 19th century [2] [3] and later on by the Multiple-Use Sustained Act (MUSYA) passed by the US Congress on June 12, 1960 in order to restore balance between the forest industry and other users. Since this time, one observation persists about multiple-use forestry (MUF), it is a vague concept that has as many interpretations as people involved [4]. To add to the complexity, MUF also refers to the management of ecosystem services and functions to take into consideration multiple aspects of forests. Instead of the tangible uses, forest managers tend towards the multifunctionality of forests where intangible ecosystem services such as carbon sequestration, water and soil quality, and biodiversity are also considered [5] [6] [7]. The importance of diverse goods and functions was acknowledged internationally after the Rio Convention in 1992. This is the reason why multifunctionality or multi-use land management is now the reference concept. Although the scientific community has proved the importance of ecosystem services, forests are still looked at through a utilitarian lens. More precisely, Scott [8] speaks of "fiscal forestry" when referring to modern forestry. Despite numerous demonstrations that prove that considering many functions increases economic value [5] [9], most of the commercial forests are still reduced to a single good (wood) and a single function (finan- 
cial).

Bjärstig and Sténs [10] defined multifunctionality as an array of services and functions that are provided by the land for the benefit of the people and their environment. However, the forests are managed in order to respect the sustained yield doctrine, which has been described as "the 'holy grail' of foresters all over the world for more or less two centuries" ([11], p. 7). Openly criticized, sustained yield is mostly a front to maximize annual yield forever [12]. Forests are still cut, and other users are dealing with the effects while the opposite situation is rarely observed. In this respect, German and Finnish examples show that the shift in forest policies from profit-oriented to common welfare forestry is not yet effective [13] [14]. While some forest areas are dedicated to conservation and other uses, it is rarely observed in so-called commercial forest areas.

That said, multifunctionality is not typical to forestry. In this respect, a lot of work has been done in agriculture [15] [16] [17]. In agricultural sciences, studies on multifunctionality are well represented. However, there is a lack of research on "the so-called soft landscape values such as biodiversity, cultural heritage, recreation and aesthetics" [15]. Rossing et al. [16] did a large study to analyse modelling approaches in France, Germany and the Netherlands with the goal of evaluating the inclusion of multifunctionality in agricultural models. The main conclusion of the study was that there was a distinct lack of social values in the models. This idea is supported by the fact that it has been largely recognized that cultural ecosystem services are under-represented in research and policies [18] [19] [20] [21] compared to other services or functions.

Depending on the purpose of the study, multifunctionality can take a variety of forms and focus on a wide variety of functions. Thus, it is difficult to identify, which are the basic functions considered when talking about "multifunctionality". After doing a complete literature review on rural multifunctionality, Gomez-Limon et al. [22] proposed four general functions: 1) economic functions because rural regions provide marketable goods and services, 2) environmental functions since these regions are known to provide plenty of regulatory and support functions such as water and air quality, biodiversity protection and so on, 3) residential functions because rural and urban citizens choose the rural regions for residential purposes and leisure and 4) recreational functions since rural regions are a place of choice to practice a multitude of outdoor activities. These four functions are directly linked to social considerations.

The inclusion of a plethora of concerns can take different forms on a temporal and spatial scale. Brandt and Vejre [23] have identified three different forms. The first is based on the spatial scale to identify different functions in different zones. A forest land-use specialization is then adopted, but it is contradictory to multiple-use forestry [24]. The second form aims to include different functions in the same area but at a different time. Temporary interruptions of forest activities would occur when functions are overlapping. Finally, the third would be the "real multifunctionality" where a diversity of functions applies at the same time on the same land unit. 
Four forest management paradigms have been identified to position forestry practices on a utilitarian gradient. The four categories are industrial forestry, sustainable yield/classical multi-use forestry, ecosystem management and social forestry [25]. Thus, the main pattern of the classical multi-use forestry is that timber production remains the primary objective while the other functions are collateral effects, and rarely the management goal. Forest management paradigms are related to societal values. For example, industrial forestry reveals a timber primacy in order to increase timber consumption, in opposition to sustainable yield, ecosystem management and social forestry, where conservation, environmental and societal values are mainly considered [26]. In a context where forest resources are mainly public, considering the needs and expectations of society is a prerogative to align forest management with the social vision.

Hence, public participation is a key element in a forest management context. It is defined as the sharing of information between individuals, communities and stakeholder groups to express interests in order to have influence on forest management decisions [27]. That said, public participation takes various forms. Depending on the nature of the decision to be made, different characteristics can be analyzed to assess the effectiveness of the process. Among these characteristics, the degree of process openness, the degree of public influence on the decision making and public involvement in the decision making are key elements that impact legitimacy and social acceptability of the decisions that are made [28].

\subsection{The Quebec Forest Context}

In Canada, forest management is under provincial jurisdiction. In our study we focus on the case of the province of Quebec as it presents a typical case of political adaptation due to international agreements. Quebec is covered by 761,100 $\mathrm{km}^{2}$ of forests, where $346,140 \mathrm{~km}^{2}$ are commercial forests and about $81 \%$ of these are publicly owned. The total annual allowable cut for $2019-2023$ is $34,148,000$ $\mathrm{m}^{3}$ per year. As in many other countries and states, the province of Quebec has adopted a new forest regime based on sustainable management goals, the Sustainable Forest Development Act [29]. The previous forest regime was known to give more freedom to industries in harvest planning, but nowadays the province's Ministry of forests has that responsibility. The second paragraph of the first article of the new legislation clearly positions integrated resource and land management as a priority in the province: "This Act establishes a forest regime designed to ensure integrated and regionalized resource and land management (IRLM) based on clear, consistent objectives, measurable results and the accountability of managers and users of the forest". The official ILRM definition is the following:

"Integrated land and resource management (ILRM) is a cooperative and consultative management process. It gathers all stakeholders, managers, and interest-bearing public and private groups for a given area. This conti- 
nuous process aims to include, from the start of planning and throughout, their visions for land development based on the conservation and enhancement of all the resources and forest functions.

The result is an integrated and concerted planning and implementation of the resource and land management plans. The ILRM contributes to increase the benefits and impacts for the communities to likewise optimize land and resource use" [translated from 25].

Although the concept of IRLM only appears in recent legislation, it is not a new approach in forest management. Starting in the 1970s and until the end of the 1990s, many ILRM pilot projects have been implemented on provincial public land in order to assess the positive and negative aspects of the concept [31]. Although no projects proved sustainable over time, they made it possible to set up the current local integrated land and resource management panels (LILRMP), which are the main tool used to implement public participation in forest planning. Moreover, given that the concept is now clearly stated in the legislation, this provides greater backing to develop projects that aim to achieve ILRM. What should also be understood in relation to the new forest regime is that forest planning is now the responsibility of public servants (government professionals). In the previous forest act, this task was in the hands of the forest industry. At the time, the industry was also responsible for conducting public consultations to include societal concerns. It should also be noted that the emergence of forest certification encouraged the forest industry to consider the social aspects of forest management.

Nowadays, public participation is defined in the legislation. Two main public participation tools are used. The first is a standard public consultation on integrated forest management plans that are addressed to regional populations who can make comments. The second tool is the LILRMP that ensures the interests and the concerns of the different stakeholders are considered in the integrated forest management plans. These panels are representative of the regional stakeholders and they have the mandate to define local sustainable forest development objectives and harmonization measures [29]. A nuance must however be made concerning their role, as they are not responsible for the decision-making process; they rather have a role of providing recommendations. Also, it is important to not confuse the role of LILRMP with ILRM, as they have completely different purposes in the sustainable forest management process. Finally, the ultimate tool used to implement the ILRM process is the integrated forest management plan that results from the public and stakeholder recommendations, and also from the interactions of the forest industry and the professionals who work for the government. Thus, the ILRM process already includes a variety of structures and interactions between them (Figure 1).

\subsection{Aims}

Several studies carried out under the former forest regime have criticized the 


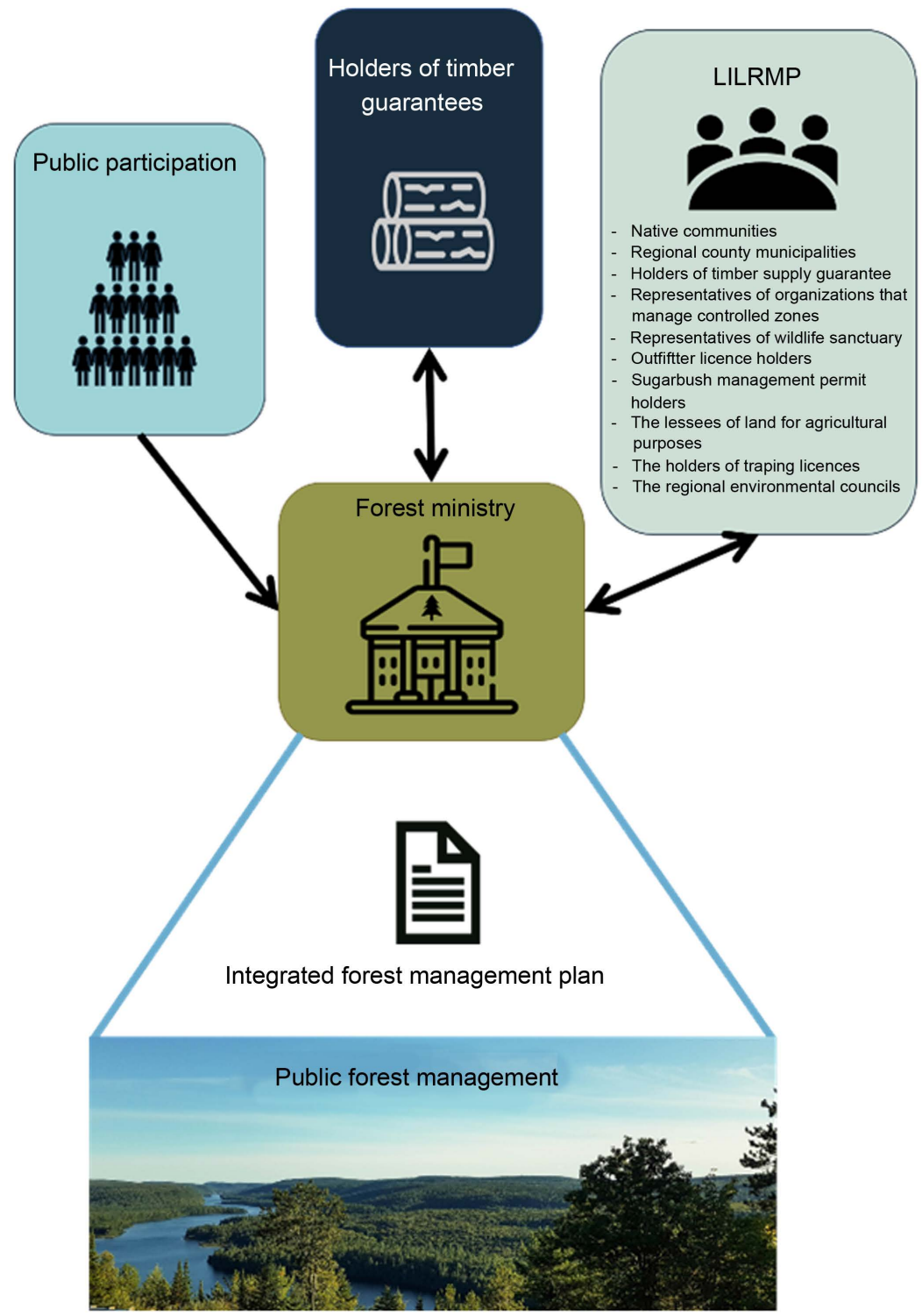

Figure 1. Structures and interactions usedto implement the ILRM process in Quebec. The arrows indicate the direction of communication between the structures (Photo reference: Rémi Orts, https://pixabay.com/fr/photos/canada-landscape-nature-couleurs-3698265/, accessed on 04.07.2020).

public participation tools [32] [33] [34] without necessarily focusing on ILRM implementation, but rather by focusing on local governance in general [35]. It is in this context that the present study aims to assess the implementation of the ILRM process from the perspective of the professionals having the mandate to carry out the implementation. More precisely, three sub-objectives were identified. The first sub-objective is to clarify the ILRM definition with respect to the ground reality. The second sub-objective is to identify the main challenges associated with the implementation of the theoretical concept. Finally, considering the elements presented in the two previous sub-objectives, the last sub-objective is to propose a realistic and improved concept model. 


\section{Materials and Methods}

This study is based on the case of the province of Quebec and assesses the implementation of the multiple-use theoretical concept, ILRM. Even if the multiple-use concept has been greatly studied, little has focused on the specific case of Quebec. To do so, semi-structured interviews were conducted with experts in seven of the seventeen administrative regions of the province for a total of 31 interviewees. Within the context of this study, experts are considered as government professionals and local panel coordinators. Our approach is inspired by grounded theory, a flexible method that allows researchers to assess social processes by direct data collection to test a theoretical framework [36]. In strict grounded theory, the theoretical framework emerges from the data [37]. Our approach is based on the existing framework of the ILRM concept, but the data analysis allows us to identify new perspectives to implement the concept. The administrative regions were selected based on demographic and territorial data (Table 1).

Table 1. Demographic, forest and ILRM characteristics of the selected administrative regions.

\begin{tabular}{|c|c|c|c|c|c|c|}
\hline \multirow[b]{2}{*}{$\begin{array}{l}\text { Administrative } \\
\text { regions }\end{array}$} & \multicolumn{2}{|c|}{ Demographic data $^{a}$} & \multicolumn{4}{|c|}{ Territorial data } \\
\hline & $\begin{array}{l}\text { Population } \\
\text { (n) }\end{array}$ & $\begin{array}{l}\text { Average } \\
\text { annual } \\
\text { growth } \\
\text { rate }(\%)\end{array}$ & $\begin{array}{c}\text { Forest } \\
\text { area } \\
\left(\mathrm{km}^{2}\right)^{\mathrm{b}}\end{array}$ & $\begin{array}{l}\text { Proportion } \\
\text { of public } \\
\text { forest }(\%)^{b}\end{array}$ & $\begin{array}{l}\text { Forest } \\
\text { type }\end{array}$ & $\begin{array}{l}\text { Number of } \\
\text { tourists in } \\
2017(000)^{c}\end{array}$ \\
\hline Côte-Nord & 91,546 & -7.4 & 212,681 & 98.83 & $\begin{array}{c}\text { Coniferous } \\
\text { (homogenous) }\end{array}$ & 217 \\
\hline Gaspésie & 91,442 & -5.4 & 19,413 & 80.15 & $\begin{array}{l}\text { Coniferous } \\
\text { and mixed } \\
\text { (homogenous) }\end{array}$ & 887 \\
\hline Lanaudière & 507,154 & 10.2 & 10,213 & 75.85 & $\begin{array}{c}\text { Deciduous } \\
\text { and mixed } \\
\text { (heterogenous) }\end{array}$ & 1570 \\
\hline Laurentides & 609,421 & 12.1 & 18,411 & 72.79 & $\begin{array}{c}\text { Deciduous } \\
\text { and mixed } \\
\text { (heterogenous) }\end{array}$ & 3117 \\
\hline Mauricie & 269,289 & 2.3 & 32,764 & 81.09 & $\begin{array}{c}\text { Coniferous } \\
\text { and mixed } \\
\text { (homogenous and } \\
\text { heterogenous) }\end{array}$ & 1948 \\
\hline Outaouais & 392,785 & 8.2 & 28,003 & 79.90 & $\begin{array}{c}\text { Deciduous } \\
\text { and mixed } \\
\text { (heterogenous) }\end{array}$ & 1887 \\
\hline $\begin{array}{l}\text { Saguenay-Lac } \\
\text { Saint-Jean }\end{array}$ & 276,509 & -0.4 & 89,153 & 94.97 & $\begin{array}{c}\text { Coniferous } \\
\text { and mixed } \\
\text { (homogenous and } \\
\text { heterogenous) }\end{array}$ & 1518 \\
\hline Quebec province & $8,394,034$ & 7.9 & 905,792 & 92.16 & - & 36,572 \\
\hline
\end{tabular}

${ }^{\mathrm{a} D a t a}$ from the Institut de la statistique du Québec [38]; ${ }^{\mathrm{b}}$ Data from ministère des Fôrets, de la Faune et des Parcs [39]. Data are for the entire province and not only for the commercial forest; ${ }^{c}$ Estimation from the ministère du Tourisme for the overall tourists in 2017 [40]. 
The first step of the exploration scheme was a literature review of scientific papers and government documents to identify every element that referred to the ILRM process. The aim of the review was to identify the ILRM related concepts. Based on the review, a preliminary interview guide was developed. The second step was the validation of the draft version of the interview guide with a panel coordinator from an administrative region that is not included in our study. Thirdly, the official interviews were conducted with an adapted version of the guide. A flexible structure was adopted for the interviews and the guide was further adapted during the process, mostly to eliminate redundant questions. To ease the discussion and to have truthful answers from the interviewees, two to three interviews were carried out in each administrative region, one with officials and one with the panel coordinator. Fourthly, the analysis of the interviews was carried out by using a combination of structural, descriptive and evaluation codes in a first cycle of coding, followed by a second-cycle of pattern coding [41]. The structural coding aims to identify phrases that refer to the research questions. The descriptive coding aims to simplify participant statements into key words referring to the topics of the interview. The evaluation coding aims to evaluate perspectives across the multiple regions used in this study. Finally, the second-cycle pattern coding aims to review the first-cycle codes to refine the analysis and simplify the results. The analysis allowed us to identify the main elements of the four sections enumerated in the interview guide. At the same time, we noted all the emerging codes that were not included in any sections of the interview guide. These codes allow us to bring new perspectives related to ILRM implementation.

\section{Interview Guide and Sections}

The interview guide was divided into four sections. The first section aimed to assess the general professional background of the participant to determine their level of familiarity with the ILRM process. The second section assessed the general understanding of the participants concerning the ILRM concept, while the third section concerned the regional implementation of the ILRM. In the fourth section, the participants were asked to express their level of agreement concerning multiple elements that are included in the ILRM definition given by Desrosiers [30]. More precisely, the definition was divided into 12 characteristics, some that appear directly in the definition and others that are implicit in relation to the defined economic benefits (Table 2). The respondents were then asked to say whether they agreed or disagreed with the statement. Finally, in the last section, we asked them what the ideal design would be if they could modify the current ILRM model. In this section, we also questioned them on their future expectations concerning ILRM implementation.

\section{Results and Discussion}

Fifteen semi-structured interviews were conducted from February 1st, 2018 to 
Table 2. List of the elements included in the ILMR definition and presented in the fourth section of the interview.

\begin{tabular}{ll}
\hline In your opinion, are the following elements or statements associated with ILRM? \\
\hline 1 & Cooperative process \\
3 & Consultation process \\
4 & Affects all stakeholders equally \\
5 & Touches collective interest \\
6 & Aims to integrate issues upstream \\
7 & Aims for continuous integration of the issues \\
8 & Aims to develop the land \\
9 & Aims to maximize the economic benefits for timber \\
10 & Aims to maximize the economic benefits for all forest resources \\
11 & Aims for optimal land development \\
12 & Aims for resource conservation \\
\hline
\end{tabular}

${ }^{*}$ Features that are implicit in the ILRM definition.

April 3rd, 2018 with 31 ILRM experts (E1 to E31). From this sample, 21 experts had worked for more than 5 years with ILRM.

\subsection{Clarification of the ILRM Definition}

\subsubsection{Related and Non-Related Characteristics}

For the first objective of this paper, which was to clarify the definition of the ILRM concept, it was possible to divide the main elements that have been identified into three groups of characteristics (Table 3).

All the experts validated the fact that ILRM is a process that integrates the issues upstream of forest management planning. Also, new issues can be integrated throughout the process. In addition, ILRM is a consultative process. However, we observed various opinions related to the nature of cooperation associated with the ILRM. Although a large majority of the respondents identified ILRM as a process that affects the collective interest, four respondents said the opposite. There are a variety of positions related to the role of land use planning and development. Respondents wondered about the semantics of the terms used, since development can take various forms. Only eleven respondents agreed that the ILRM aims for optimal land development. One of the experts interviewed presented the following nuance about development in an ILRM context:

"[...] [ILRM], it does not aim to develop the land, but it must consider the development of the land. [...] [ILRM]. It must allow the area to develop, that resources can develop and must not prevent development." (E28)

Regarding the aim of enhancing the land, most of the respondents agreed that the ILRM addresses land use planning/development. Related to the ILRM aim of 
Table 3. Respondent's views of the 11 characteristics extrapolated from the Desrosiers definition [30], where green colour shows elements that are fully agreed by respondents, yellow the elements that are mostly agreed by respondents and red the elements that are mostly disagreed by respondents.

\begin{tabular}{ccc}
\hline Elements included or extrapolated from Desrosiers' definition [30] & Yes & No \\
\hline $\begin{array}{c}\text { Aims to integrate issues upstream } \\
\text { Aims for a continuous integration of issues } \\
\text { Consultation process }\end{array}$ & 31 & 0 \\
Touches collective interest & 30 & 1 \\
Aims to enhance the land & 27 & 4 \\
Aims for the development of the land & 26 & 5 \\
Cooperative process & 22 & 9 \\
Aims for an optimal land development & 20 & 11 \\
Aims at conserving the resources & 11 & 20 \\
Aims to maximize economic benefits for all forest resources & 11 & 20 \\
Aims to maximize economic benefits for timber only & 9 & 22 \\
Reach all the stakeholders equally & 6 & 25 \\
\hline
\end{tabular}

conserving forest resources, most respondents disagreed with this statement. Several underlined the conflicting nature of the ILRM concept and the so-called "glass dome" conservation where the land can no longer be used for other activities. Regarding economic aspects, we have proposed a reformulation of the elements included in the definition. Instead of talking about economic growth, we make a nuance between maximization of economic benefits for timber only and economic benefits for all forest resources. Finally, most of the respondents disagreed with the proposition that the ILRM concept is a process that affects all the stakeholders equally. This last element raises several questions regarding the implementation of the ILRM concept at a regional scale.

\subsubsection{Newly Mentioned Items}

An analysis of the interviews made it possible to identify new elements that should be included in the definition of the ILRM process. Following are the common elements that were mentioned by the experts.

First, the ILRM process should allow social equity to be achieved so that all stakeholders involved in the regional forest sector can be considered. For them, the ILRM concept is a management process whose goal is sustainable use of the forest from an economic, environmental, and societal point of view. Thus, it is also dependent on communication and the level of understanding of the stakeholders participating in the LILRMPs.

Second, it was mentioned several times that integrated management in Quebec, as applied in the field, has eliminated the land from the equation. Nowadays, integrated management is done through a forestry lens only and not through a territorial lens. Some experts have mentioned that integrated man- 
agement applied in Quebec places timber at the center of the process, thereby considering the other forest resources as limitations to management. That said, producing a forest management plan that integrates all resources and all territorial challenges is complex. Therefore, approaching land use planning from a forestry perspective can be a simpler route than to consider the territory globally.

"Integrated land and resource management is really hard [to apply]. First because it considers all activities at the same level and at the same stage. [...] it can't maximize all the activities at the same time. There may be an optimum. What you must see is if you want an optimum in terms of economic benefits, social benefits, or environmental benefits. [...] The current Quebec model of resource management is very difficult to achieve. We have no choice but to approach the ILRM process using a starting point. [...] Here it is the Ministère des Forêts, de la Faune et des Parcs. Of course, it [the Ministry] first addresses it [ILRM] through forestry, which will then include recreotourism, maple syrup production, non-timber forest products, and all the others. Yes, it's integrated management but through forest management" (E25).

Third, the experts also agreed that one of the objectives of the ILRM approach is to know the needs, values and expectations of all forest users so that everyone agrees on the forest operations to be practiced in order to respect all stakeholders, or at least the greatest number of them. The Ministry is now solely responsible for forest planning, but the tasks are multiple. It is considered as a promoter who must deliver timber to mills while respecting the values of other users. All respondents agreed that all stakeholders within the area must draw benefits from the ILRM process. All the people using the forest must state their needs and objectives and be considered during the planning process. There is a theoretical definition of the ILRM approach, but in practice several elements are overlooked. One of the experts described his theoretical vision by stressing that this is not the type of approach that is used in the field.

"It's a continuous management process that should be evolutionary [...] according to the scientific and traditional knowledge that we collect by different means and according to the evolution of land use, which sometimes multiply and change. This process should not be done, in my opinion, according to a resource as is the case in forest management [...] but should be done on a land basis. Then, the ILRM process should allow us to harmonize the values of the people who use this territory, whether these values are economic, environmental, or social, ultimately to optimize land use. [...] Is that what we do? Well, I don't think so." (E7)

\subsubsection{Other Details ILRMs}

Across all regions visited, experts clearly differentiated between ILRMs and LILRMPs. While the ILRM approach is the process that underpins land use plan- 
ning, LILRMPs represent the means that the Government of Quebec has adopted to use to implement ILRMs. One of the respondents clearly expressed the difference between the two.

"Integrated management is like the concept. We are trying to integrate several issues that concern several resources in the territory. The LILRMP is just the exchange platform where we bring together a representative of each type of stakeholder present in the area." (E26)

However, during the analysis of the results, we noted that there was sometimes an abuse of language when it came to LILRMPs, specifically referring to the concept of integrated management. This can be explained, among other things, by the fact that for some stakeholders, integrated management is mainly achieved by the LILRMP. Depending on the region, ILRM is a top-down process where the Ministry imposes its vision on the panel members. On the other hand, interviewees from several regions mentioned that the ILRM is rather a hybrid process since the framework is set up by the Ministry (top-down), but the stakeholders have the necessary tools to make recommendations to Ministry officials thereafter.

\subsection{Main Challenges of the ILRM Approach}

The following section presents results related to the second sub-objective of clearly identifying the main challenges to the implementation of ILRM.

\subsubsection{Better Communication}

First, one of the most recurrent themes related to the challenges of ILRM implementation is communication. In addition, communication needs are varied, ranging from internal communication (between ILRM stakeholders) to external communication (between ILRM stakeholders and the population). One of the major challenges to internal communications is related to the sharing of information between representatives of a group with members of the group. It should be noted that the representatives who sit on the LILRMPs are selected by their peers. However, depending on the representative and the organization he represents (number of members, location of the members, communication structures in the organization, financial and technical means of the organization), the information that is exchanged within the LILRMP is not necessarily transmitted to all members.

Some representatives are volunteers. Thus, the topics that are addressed at the meetings are not necessarily related to their expertise. Updates are sometimes necessary to ensure that all representatives understand the issues that are discussed at panel meetings. In this regard, respondents repeatedly mentioned that more resources should be allocated to provide continuing education for participants serving on the LILRMPs.

The willingness of representatives to truly represent the values, needs, and expectations of their members was raised in the interviews. Some experts note 
that it seems difficult for representatives to separate their personal interests from collective interests. Here is a quote that clearly presents this view:

"Often, we have delegates who represent a working group, but we do not feel that they truly represent the group. We feel that they represent themselves. They put their interests first and when we oblige them to focus on community interests, they are not happy. They love to hear about their little sandbox." (E5)

In an ideal world, representatives would have to know the concerns of their members and not champion their personal interests at LILRMP meetings but concentrate on collective concerns. It would be relevant to look at the framing theory to assess the diversity of positions within panels [42] [43].

It seems that participants on LILRMPs are interfering in the ILRM process. The approach of appointing representative panel members must be reviewed so that members are accountable to the organization they represent. These individuals contribute to the sustainable development of Quebec's forest resources, and their involvement must be emphasized to recognize the nobility of their active participation.

The stakeholders who participate in LILRMPs come from various backgrounds. On a daily basis, each member must manage very specific issues related to his area of activity. Within the context of LILRMPs, discussions are related to global issues. One of the major challenges with stakeholders is to succeed in creating social cohesion between them. A broad body of knowledge is required to interact with other panel members and to participate effectively in discussions. Thus, representatives are mandated to take positions on questions for which they are not necessarily trained. Having multiple participants broadens the forest management horizon and helps build an understanding of the concerns of interest groups. That said, the representative must really use his role to express the needs and expectations of the group he represents. Therefore, the ILRM process depends on individuals, as much for representatives of interest groups as for institutional representatives. Informal meetings between stakeholders improve the functioning of the panel [44]. Compared to the previous forest regulation, stakeholders can now talk with other interest groups, which is an improvement.

Regarding external communication, we note that experts and Ministry officials need to better communicate forestry practices to the population. The experts interviewed pointed out that there is a great deal of effort in this direction, but, as presented in the following excerpt, it is a process that becomes very energy-consuming for officials:

"We have had a lot of meetings [...] where we will go directly to the municipalities and we will meet the advisers and the people concerned. And often at the end of the meeting, they say 'Thank you for coming. We are happy to know.' It is reassuring, and people want meetings like this. They want the information. In return, it is extremely energy consuming for us." (E23) 
It should also be pointed out that forestry officials have not always been trained in the social sciences, including communication, sociology, and ethics. Therefore, this task may be more demanding for them. "But the fact remains that $[\ldots]$ we are not ready for the communication aspect. Then again, it's amazing how it's part of our life. [...] Well, in our training, there was no one who told us that we were going to work with partners, trying to explain to them how to do forestry, this was not the goal. You applied what you learned, your knowledge and then you did not have to share it to convince your partners. Then, this is the job we must do. To convince them, to inform them and to explain to them." (E3)

\subsubsection{Development of a "Forest Culture"}

A theme that emerged in the interviews was related to a commonvision of the forest or as expressed by the experts a "forest culture". Explaining all the forestry interventions that occur in a territory the size of Quebec is not a realistic approach. However, users and society need to be informed about the real impacts of forestry on ecosystems, and on regional socio-economic development. This is why most experts expressed the belief that the ideal ILRM model should come with the establishment of a shared vision of the forest adopted by all Quebecers. In four meetings, it was mentioned that there are shortcomings in the province with regard to a common vision of the forest or, as wished, is associated with a greater understanding of the global forest environment. The following four quotes illustrate the repetition of this theme by the experts:

"Forest culture in Quebec? We don't have it. Earn a living from the forest, sharing the territory, I find that we don't have it." (E3)

"Forest culture in Quebec has completely disappeared. At least, in the region here. To cut a tree is to kill a tree." (E24)

"We will not teach forest culture to people who live in the suburbs, that is impossible. They are the ones who will develop it if we give them the tools... if we give them the means. If after 50 years, this forest culture has been developed, so much the better. The little government official who worked his whole life for that, well at least, he will have accomplished that."

"We continue with forest culture. It's really a big shortcoming, mainly with children. Do they know that the forest is important?" (E31).

An interesting fact that we observed in the second quote is that the forest culture has disappeared. This means that it would not be impossible to get it back. However, to remedy this shortcoming, more knowledge of the forest environment must be integrated into school curricula in order to better understand the role of the forest in climate change mitigation, and also to encourage the population to position itself in relation to forestry operations. Although, forest culture is disconnected from the ILRM process, it would facilitate the coexistence of different activities on the land. This is why forest culture is a key element that needs 
to be considered in the ideal ILRM model.

In addition, a strong forest culture would improve the social acceptability of forestry practices. Social acceptability plays an important role in the forest industry. Several studies have looked at the social acceptability of different activities occurring on forested land [45] [46] [47] [48], but acceptability assessments should be done. However, practices that are acceptable to some are not necessarily acceptable to others. Thus, we believe that a stronger forest culture would allow stakeholders involved in integrated management to grasp the interests of other interest groups. It would be easier to find compromises while keeping in mind the reasons that led professionals to apply specific management decisions. Trying to improve the social acceptability of forestry operations without developing a dialogue between the stakeholders is nonsense. In its strategy for sustainable forest management, the Quebec government wants to enhance social acceptability by improving its dialogue with the public [49]. However, at no point in the strategy does it refer to the means that will be taken to establish this dialogue, which can prove to be complex to develop in certain regions and with certain citizens. A study carried out in Finland looking at the participation of stakeholders in the development of forest management plans shows that it would be irrelevant to include the whole population in the process since plans are strategic documents [50]. Thus, it would be necessary to clearly determine the times and places required to express these values to the public.

We must take the time to get to know and understand each other and then accept forestry operations that, at first, do not meet our values or our expectations. The ILRM process, as it is currently applied theoretically, allows LILRMP members to set up a dialogue to better understand the needs of each stakeholder. Also, for them to be better understood by the public, forestry operations must firstly be understood by a greater number of stakeholders. It should also be recognized that the interest of the population varies from one region to another and from one socio-economic environment to another. There is also a gap between the experts and stakeholders who sit on the LILRMPs. Interest group representatives face the challenges of ILRM only a few times a year while experts are working on these elements on a daily or weekly basis. What the government requires from representatives is sometimes disconnected from their reality, which reduces their commitment to the ILRM process. It is therefore necessary to ensure the mobilization of stakeholders regarding the issues addressed at the LILRMP meetings and to do this, participants must be confident that the time invested in these meetings will bear fruit.

The professionals who work to implement ILRM try to assist the stakeholders to make sure they understand the issues and the process. However, the professionals need more resources to do so. As mentioned previously, these professionals were generally trained in applied natural science programs. However, the mandate asked of them today is of a different nature. The forest sector must open to new disciplines such as communication, sociology, and economics to develop a dialogue with the public that has the goal of developing a stronger for- 
est culture. This idea agrees with the suggestion presented by Batavia and Nelson [51] to include more ethics in natural resource curricula.

\subsubsection{Increase the Flexibility of the Timber Harvest System}

The Quebec forest harvesting system is based on the calculation of the annual allowable cut, which allows industries to benefit from defined volumes of wood to supply their mills. In an integrated management context, we assume that the forest is managed for all the goods and services it provides. However, in the context of calculating the allowable cut, logging becomes a limitation for other resources. From a forest harvesting point of view, the consideration of other goods and services also becomes a limitation to logging. It would thus be necessary to adjust forest practices to harmonize it with other uses. It is still the old-fashioned, utilitarian vision of the forest that dominates [52].

To reduce limitations, it is possible to develop agreements related to integrated management by developing regional integrated strategies. For example, an LILRMP may determine that all landscapes around wetlands in a region must benefit from visual landscape planning to preserve aesthetics and to maintain recreational values. As currently conceived, the law tends to encourage contradictory objectives. First, the law aims to maintain the allowable cut and, secondly, it tries to achieve ILRM. However, by maintaining the allowable cut, we reduce the chances of being able to manage the forest for other resources since these other uses negatively influence the allowable cut. In this case, the primary goal is timber and it is prioritized over other uses. Several experts interviewed during the focus groups mentioned this limitation and associated it with the allowable cut. Here is a quote that presents this idea:

"[...] but the problem is that the allowable cut is always maintained. Basically, you must reach the allowable cut. This makes the maneuvering space for new solutions, new harmonization and to integrate different needs very thin. The bottom line is that the wood must be picked up. It is there, it is available, and it has been quantified. I might see adjustments at that level, but it is very sensitive. It is political. I think that it's key if we want to go further in ILRM." (E4)

In discussing forestry vocations and the intensification of forestry operations, one of the speakers mentioned the importance of optimizing the use of the land that is mainly exploited for timber:

"This is why we have to go further. For example, tell yourself that we protect $30 \%$ of the land and the rest is for industrial purposes. I said protected area, but it could be for recreation or tourism purposes or it could be for wildlife purposes. It could be for whatever, and then you be creative to make wood grow. I mean, we're still in mass forestry and that's what is holding us back.” (E7)

An expert from another region also mentions the contradiction of ILRMs 
which are still based primarily on timber volume compared to the desired model which is based on a variety of uses:

"First, if we stop managing for volume and manage for benefits, it would be a big plus. The current forest regime, like the previous one, is based on the cubic meter of wood. Of course, the boreal forest is the same, it generates more cubic meters of wood. But how much is this cubic meter per hectare worth compared to the deciduous forest $[\ldots]$ ? Our regime is much less suited to mixed and deciduous forests because we manage by the cubic meter. But when one cubic meter is worth six times more, can we afford to harvest less? Already, if we manage by dollar per hectare in forestry [...], I think we would get closer to something adapted. Then we would be able to compare with other economic impacts from other activities to find an optimum."(E25)

Adapting traditional forest management to present-day settings is necessary to integrate multiple activities [53]. However, the adaptation of forest management does not mean that we should standardize multiple-use forestry [4]. It is necessary to have forest management adapted to regional contexts. Another factor that has been mentioned repetitively is the need to break down silos. As defined by ILRM, there should be no silos if land use planning is based on all possible uses of the forest land. Thus, an ideal model should be executed according to horizontal management involving all stakeholders.

\subsubsection{Improve Forest Zoning}

From the interviews, one of the main concerns identified by the stakeholders is related to forest land use by other stakeholders. Experts have mentioned that the "not in my backyard" concept is often mentioned by stakeholders at the LILRMP meetings. In the best of all worlds, each stakeholder could use the land according to their needs. Several uses can overlap the same area. It would be necessary to better define land use allocations to reduce potential conflicts. That said, defining the allocation of forest land is a laborious task that should be developed with participatory and inclusive approaches.

It is also on this type of question that stakeholders wish to be consulted, and not on the technical aspects of forest management. "People want to be consulted on land use planning. They want to brainstorm together, collectively, and fairly... about multi-resource allocation." (E22). However, it is not the mission of the Ministry of Forest, Wildlife and Parks to define land uses. This is the role of another ministry, the Ministry of Energy and Natural Resources. A better definition of the activities that can occur on forest land would facilitate the cohabitation of stakeholders who would know a priori what can or cannot take place on the land. Prioritization of uses would make it possible to establish priority areas for timber production while other sectors would have a primary vocation of recreation and tourism or wildlife exploitation. Also, multi-purpose areas could be established. For the moment, Quebec forest land has a primary vocation of 
timber production and other activities limit forestry. Opposing visions automatically bring conflict between the stakeholders. The ideal ILRM model would base the development of forest land not on the volume of wood, but on the activities that are practiced [54]. The allocations would be adapted to regional realities.

To facilitate the allocation limits and optimize land use, an economic model which quantifies the economic impacts of the activities in each area would allow comparisons between activities using a common reference measurement, the dollar generated per hectare.

"So, I imagine that if we were able to quantify the weight of a wildlife activity compared to a forestry activity, it would allow us to decide whether we give up one activity in favor of another. [...] It would be worth asking these questions because right now we are taking everything at the same level, and we say that everything is important." (E27)

\subsubsection{Operational (Short-Term) vs Strategic (Long-Term) Level}

Most of the stakeholders who participate in LILRMPs are volunteers. They generally have more operational concerns (short-term horizon) than experts who try to implement strategic recommendations (long-term horizon). It can be difficult for professionals to address the concerns of stakeholders, thereby creating dissatisfaction and disengagement within the panels. More commonly, the operational level is associated with the harmonization of operations, which represent short-term goals.

As to strategic issues that have a long-term outlook, the Sustainable Forest Development Act provides that participants in LILRMPs must develop local planning objectives (LPO). It is thus understandable that the wishes of the stakeholders and regulations are out of sync. On numerous occasions during the interviews, the experts referred to harmonization and LPOs. Two stress that integrated management is not harmonization since it rather refers to short-term issues, which, according to them, is contradictory to ILRM since this concept focuses on strategic and long-term planning. One of the experts totally disagreed with this vision and stressed that harmonization is an integrated management tool although it is a tool with a short-term outlook. Thus, there is no consensus on the role of harmonization in ILRM. A clarification should be made in the reference documents linked to ILRM.

\subsection{Updated Definition and Model}

This last section proposes a new definition and an adapted model of ILRM that is more consistent with reality and expressed challenges. To be coherent with the results, the name of the concept should change to Integrated Forest Resource Management (IFRM). Also, we propose a simplified definition of the concept to meet social expectations, which is not the case with the current definition:

IFRM would be a regional consultation process between the stakeholders of a designated forest area. This continuous process aims to integrate issues from the start of the planning and throughout the process. This process aims to achieve 
social equity by taking into consideration the needs and values of the stakeholders. It would also be necessary to modify the LILRMPs to Local Integrated Forest Resource Management panels (LIFRMPs).

An enhanced IFRM approach would consider various changes such as the improvement of internal and external communication, a greater flexibility of the timber harvest process, forest zoning and improve the panels to better address stakeholders' concerns. A revision of institutional tools such as forest laws and regulations will also be necessary to achieve these changes. IFRM, contrary to ILRM, lowers the expectations of stakeholders and presents an approach that is closer to reality. By using a more accurate definition, the stakeholders will also be more inclined to participate in the panels' work, and over a long period, it might improve public participation and reduce the number of conflicts and negative perceptions of panels. Rather than focusing on the aspects that are not tackled by the panels, it would now be possible to concentrate on forest related issues rather than on territorial issues that cannot be addressed by the Ministry of forests. Also, the level of participation might vary from one panel to another depending on their inner cohesion level and their level of intervention (strategic vs operational). Finally, the type of intervention is important when addressing forest issues, but cohesion has a greater importance for facilitating participation, as it influences the ability to work in a team.

\section{Conclusions}

The present study differs from others done in ILRM since it clearly identifies the main challenges that need to be addressed to reach expert concerns and, to some extent, stakeholders concerns. A new definition and model of ILRM were developed to better respond to social considerations. In this sense, it is more suitable to lower social expectation when proposing an institutional concept and when linking theoretical, regulatory, and practical perspectives of multiple-use forest management, a gap is observed. Theoretical and regulatory tools tend to be based on sustainable forest management (SFM) principles. However, when looking at the main challenges that have been identified, there are still a lot of barriers to achieving multiple-use forestry or as-called in Quebec, ILRM. At some point, it is normal for the theory to be based on ambitious approaches that aim to enhance forest development. Regulatory tools consider the theory, but the fact that the gap between the desires of the stakeholders and reality is persistent raises the most questions. Thus, created expectations are not met by actions. The assessment of the experts' perspective on ILRM can show that even with their expertise, the experts pointed out flaws when reaching out to the theoretical approach. Adjustments must be made so that stakeholder expectations are better achieved. The definition that we propose adheres to theory while being more realistic in its implementation.

As expressed by the experts, the ILRM process does not affect all stakeholders equally and the lack of recognition for the recommendations made by ILRMP members can lead to dissatisfaction. It is necessary to consider the real expecta- 
tions of the stakeholders to keep them motivated. The stakeholders are motivated about the territory they use and because of their voluntary involvement in the ILRM process, it seems difficult to ask them to comment on issues that are disconnected from their reality. On a larger scale, SFM can be achieved if decision-makers invest in plans to establish a strong common-vision of the forest in society. Otherwise, conflicts and constraints will always remain central to discussions that take place during public consultation processes.

Even if participatory processes are implemented, they are supposed to position the stakeholders at the center of the process. The current "command and control" way of managing natural resources still reflects the predominance of the interests of the timber industry. Contrary to international tendencies in forest management, the Quebec case is a clear illustration of this gap. Despite laws, regulations, and theory, SFM, social and cultural principles remain binding objectives to wood harvesting. However, the real limitation to multiple-use forest management is the annual allowable cut. Specializations and real integrated land use plans must be implemented in Quebec to implement multiple uses forestry. Further research should continue to explore this alternative even though many examples of multi-use management have been tried. Also, an economic valuation of all goods and services rendered by the forest should be carried out in a pilot project to better understand the territorial trade-offs. It would then be possible to assess the trade-offs of the different potential usages of a multifunctional territory.

\section{Acknowledgements}

This research was funded by Génome Québec/Genome Canada [243FOR] and Quebec Research Funds for Society and Culture (FRQSC). We wish to thank all the experts interviewed in this study and Carole Coursole for the stylistic revision of the manuscript.

\section{Conflicts of Interest}

The authors declare no conflict of interest.

\section{References}

[1] ITTO (1998) Manual for the Application of Criteria \& Indicators for Sustainable Mgmt of Natural Tropical Forests.

[2] Nelson, R.H. (2013) Multiple-Use Forest Management versus Ecosystem Forest Management: A Religious Question? Forest Policy and Economics, 35, 9-20. https://doi.org/10.1016/j.forpol.2013.06.003

[3] Muir, J. (1901) Our National Parks. https://doi.org/10.5962/bhl.title.53718

[4] Hoogstra-Klein, M.A., Brukas, V. and Wallin, I. (2017) Multiple-Use Forestry as a Boundary Object: From a Shared Ideal to Multiple Realities. Land Use Policy, 69, 247-258. https://doi.org/10.1016/j.landusepol.2017.08.029

[5] Triviño, M., Juutinen, A., Mazziotta, A. and Miettinen, K. (2015) Managing a Boreal Forest Landscape for Providing Timber, Storing and Sequestering Carbon. Ecosys- 
tem Services, 14, 179-189. https://doi.org/10.1016/j.ecoser.2015.02.003

[6] Triviño, M., Pohjanmies, T., Mazziotta, A., Juutinen, A., Podkopaev, D., Le Tortorec, E. and Mönkkönen, M. (2017) Optimizing Management to Enhance Multifunctionality in a Boreal Forest Landscape. Journal of Applied Ecology, 54, 61-70. https://doi.org/10.1111/1365-2664.12790

[7] Safeeq, M., Grant, G.E., Lewis, S.L. and Hayes, S.K. (2020) Disentangling Effects of Forest Harvest on Long-Term Hydrologic and Sediment Dynamics, Western Cascades, Oregon. Journal of Hydrology, 580, Article ID: 124259. https://doi.org/10.1016/j.jhydrol.2019.124259

[8] Scott, J.C. (1998) Seeing like a State: How Certain Schemes to Improve the Human Condition Have Failed. Yale University, New Heaven, Vol. 33.

[9] Juutinen, A. (2008) Old-Growth Boreal Forests: Worth Protecting for Biodiversity? Journal of Forest Economics, 14, 242-267. https://doi.org/10.1016/j.jfe.2007.10.003

[10] Bjärstig, T. and Sténs, A. (2018) Social Values of Forests and Production of New Goods and Services: The Views of Swedish Family Forest Owners. Small-Scale Forestry, 17, 125-146. https://doi.org/10.1007/s11842-017-9379-9

[11] Grober, U. (2007) Deep Roots: A Conceptual History of "Sustainable Development" (Nachhaltigkeit). WZB Discuss. Pap. P 2007-0022007, 1-30.

[12] Behan, R.W. (1978) Political Popularity and Conceptual Nonsense: The Strange Case of Sustained Yield Forestry. Environmental Law, 8, 309-342.

[13] Borrass, L., Kleinschmit, D. and Winkel, G. (2017) The “German Model” of Integrative Multifunctional Forest Management-Analysing the Emergence and Political Evolution of a Forest Management Concept. Forest Policy and Economics, 77, 16-23. https://doi.org/10.1016/j.forpol.2016.06.028

[14] Ruppert-Winkel, C. and Winkel, G. (2011) Hidden in the Woods? Meaning, Determining, and Practicing of "Common Welfare" in the Case of the German Public Forests. European Journal of Forest Research, 130, 421-434. https://doi.org/10.1007/s10342-009-0335-X

[15] Haaland, C., Fry, G. and Peterson, A. (2011) Designing Farmland for Multifunctionality. Landscape Research, 36, 41-62. https://doi.org/10.1080/01426397.2010.536202

[16] Rossing, W.A.H., Zander, P., Josien, E., Groot, J.C.J., Meyer, B.C. and Knierim, A. (2007) Integrative Modelling Approaches for Analysis of Impact of Multifunctional Agriculture: A Review for France, Germany and the Netherlands. Agriculture, Ecosystems \& Environment, 120, 41-57. https://doi.org/10.1016/j.agee.2006.05.031

[17] Romstad, E., Vatn, A., Rørstad, P.K. and Søyland, V. (2000) Multifunctional Agriculture Implications for Policy Design.

[18] Daniel, T.C., Muhar, A., Arnberger, A., Aznar, O., Boyd, J.W., Chan, K.M.A., Costanza, R., Elmqvist, T., Flint, C.G., Gobster, P.H., et al. (2012) Contributions of Cultural Services to the Ecosystem Services Agenda. Proceedings of the National Academy of Sciences of the United States of America, 109, 8812-8819. https://doi.org/10.1073/pnas.1114773109

[19] Hirons, M., Comberti, C. and Dunford, R. (2016) Valuing Cultural Ecosystem Services. Annual Review of Environment and Resources, 41, 545-574. https://doi.org/10.1146/annurev-environ-110615-085831

[20] Hernández-Morcillo, M., Plieninger, T. and Bieling, C. (2013) An Empirical Review of Cultural Ecosystem Service Indicators. Ecological Indicators, 29, 434-444. https://doi.org/10.1016/j.ecolind.2013.01.013 
[21] Angarita-Baéz, J.A., Pérez-Miñana, E., Beltrán Vargas, J.E., Ruiz Agudelo, C.A., Paez Ortiz, A., Palacios, E. and Willcock, S. (2017) Assessing and Mapping Cultural Ecosystem Services at Community Level in the Colombian Amazon. International Journal of Biodiversity Science, Ecosystem Services \& Management, 13, 280-296. https://doi.org/10.1080/21513732.2017.1345981

[22] Gomez-Limon, J.A., Vera-Toscano, E. and Rico-Gonzalez, M. (2012) Measuring Individual Preferences for Rural Multifunctionality: The Importance of Demographic and Residential Heterogeneity. Journal of Agricultural Economics, 63, 1-24. https://doi.org/10.1111/j.1477-9552.2011.00325.x

[23] Brandt, J. and Vejre, H. (2004) Multifunctional Landscapes. WIT Press, Southampton, Boston.

[24] Zhang, Y. (2005) Multiple-Use Forestry vs. Forestland-Use Specialization Revisited. Forest Policy and Economics, 7, 143-156. https://doi.org/10.1016/S1389-9341(03)00028-5

[25] Winkel, G. (2014) When the Pendulum Doesn't Find Its Center: Environmental Narratives, Strategies, and Forest Policy Change in the US Pacific Northwest. Global Environmental Change, 27, 84-95. https://doi.org/10.1016/j.gloenvcha.2014.04.009

[26] Glück, P. (1987) Social Values in Forestry. Ambio, 16, 158-160.

[27] Beckley, T.M., Parkins, J.R. and Sheppard, S.R.J. (2005) Public Participation in Sustainable Forest Management: A Reference Guide. Edmonton, Alberta.

[28] Steelman, T.A. and Ascher, W. (1997) Public Involvement Methods in Natural Resource Policy Making: Advantages, Disadvantages and Trade-Offs. Political Science, 30, 71-90. https://doi.org/10.2139/ssrn.1931047

[29] Éditeur officiel du Québec Sustainable Forest Development Act. http://legisquebec.gouv.qc.ca/en/showdoc/cs/A-18.1/20100401

[30] Desrosiers, R., Lefebvre, S., Munoz, P. and Pâquet, J. (2010) Guide sur la gestion intégrée des ressources et du territoire: Son application dans l'élaboration des plans d'aménagement forestier intégré.

[31] (1997) Ministère des Ressources naturelles Planifier la gestion intégrée des ressources et du milieu forestier-Une démarche; Québec, Canada.

[32] Tardif, J., Bissonnette, J.F. and Dupras, J. (2017) La participation publique dans la gestion des forêts du Québec: Réorganisation de la concertation régionale dans un contexte institutionnel en transition. Forestry Chronicle, 93, 58-70. https://doi.org/10.5558/tfc2017-011

[33] Martineau-Delisle, C. and Nadeau, S. (2010) Assessing the Effects of Public Participation Processes from the Point of View of Participants: Significance, Achievements, and Challenges. Forestry Chronicle, 86, 753-765. https://doi.org/10.5558/tfc86753-6

[34] Bouthillier, L. and Roberge, A. (2007) Les intentions des programmes de participation du public appliqués par l'industrie forestière: État de la situation au Québec. Forestry Chronicle, 83, 810-817. https://doi.org/10.5558/tfc83810-6

[35] Chiasson, G. and Leclerc, É. (2013) La gouvernance locale des forêts publiques québécoises. Les Presse, Québec.

[36] Charmaz, K. and Belgrave, L.L. (2015) Grounded Theory. In: The Blackwell Encyclopedia of Sociology, John Wiley \& Sons, Ltd., Hoboken, 1-6. https://doi.org/10.1002/9781405165518.wbeosg070.pub2

[37] Guillemette, F. (2006) L'approche de la Grounded Theory; pour innover? Recherches Qualitatives, 26, 32-50. 
[38] (2018) Institut de la statistique du Québec Le bilan démographique du Québec; Québec.

[39] (2019) MFFP Ressources et industries forestières du Québec, portrait statistique 2018; Québec.

[40] Ministère du Tourisme Le tourisme en bref au Québec en 2017. http://www.tourisme.gouv.qc.ca/intelligence-affaires/tourisme-bref-2017.html\#titre6

[41] Saldana, J. (2010) The Coding Manual for Qualitative Researches. SAGE, Los Angeles.

[42] Vincent, S.G. and Shriver, T.E. (2009) Framing Contests in Environmental Decision-Making: A Case Study of the Tar Creek (Oklahoma) Superfund Site. American Journal of Environmental Sciences, 5, 164-178. https://doi.org/10.3844/ajessp.2009.164.178

[43] Lidskog, R., Sundqvist, G., Kall, A.S., Sandin, P. and Larsson, S. (2013) Intensive Forestry in Sweden: Stakeholders' Evaluation of Benefits and Risk. Journal of Integrative Environmental Sciences, 10, 145-160. https://doi.org/10.1080/1943815X.2013.841261

[44] Idrissou, L., van Paassen, A., Aarts, N. and Leeuwis, C. (2011) From Cohesion to Conflict in Participatory Forest Management: The Case of Ouémé Supérieur and N'Dali (OSN) Forests in Benin. Forest Policy and Economics, 13, 525-534. https://doi.org/10.1016/j.forpol.2011.06.001

[45] Ribe, R.G. (2006) Perceptions of Forestry Alternatives in the US Pacific Northwest: Information Effects and Acceptability Distribution Analysis. Journal of Environmental Psychology, 26, 100-115. https://doi.org/10.1016/j.jenvp.2006.05.004

[46] Wyatt, S., Rousseau, M.H., Nadeau, S., Thiffault, N. and Guay, L. (2011) Social Concerns, Risk and the Acceptability of Forest Vegetation Management Alternatives: Insights for Managers. Forestry Chronicle, 87, 274-289. https://doi.org/10.5558/tfc2011-014

[47] Nilausen, C., Gélinas, N. and Bull, G. (2016) Perceived Acceptability of Implementing Marker-Assisted Selection in the Forests of British Columbia. Forests, 7, 286. https://doi.org/10.3390/f7110286

[48] Western, J.M., Cheng, A.S., Anderson, N.M. and Motley, P. (2017) Examining the Social Acceptability of Forest Biomass Harvesting and Utilization from Collaborative Forest Landscape Restoration: A Case Study from Western Colorado, USA. Journal of Forestry, 115, 530-539. https://doi.org/10.5849/JOF-2016-086

[49] MFFP (2015) Stratégie d'aménagement durable des forêts. Québec.

[50] Kangas, A., Saarinen, N., Saarikoski, H., Leskinen, L.A., Hujala, T. and Tikkanen, J. (2010) Stakeholder Perspectives about Proper Participation for Regional Forest Programmes in Finland. Forest Policy and Economics, 12, 213-222. https://doi.org/10.1016/j.forpol.2009.10.006

[51] Batavia, C. and Nelson, M.P. (2016) Conceptual Ambiguities and Practical Challenges of Ecological Forestry: A Critical Review. Journal of Forestry, 114, 572-581. https://doi.org/10.5849/jof.15-103

[52] Kant, S., Wang, S., Deegen, P., Hostettler, M., von Detten, R., Howard, T., Laband, D., Montgomery, C., Robert, N., Sekot, W., et al. (2013) New Frontiers of Forest Economics. Forest Policy and Economics, 35, 1-8. https://doi.org/10.1016/j.forpol.2013.06.002

[53] Horstkotte, T., Lind, T. and Moen, J. (2016) Quantifying the Implications of Different Land Users' Priorities in the Management of Boreal Multiple-Use Forests. 
Environmental Management, 57, 770-783.

https://doi.org/10.1007/s00267-015-0643-5

[54] Kant, S. (2009) Recent Global Trends in Forest Tenures. Forestry Chronicle, 85, 849-858. https://doi.org/10.5558/tfc85849-6 